\title{
BMJ Open Non-linear relationship between basal serum albumin concentration and cardiac arrest in critically ill patients with end-stage renal disease: a cross- sectional study
}

\author{
Yong-Qin Zeng (D) , ${ }^{1}$ Zuo-An Qin, ${ }^{2}$ Zi-Wei Guo, ${ }^{1}$ Bo Li, ${ }^{1}$ Hai-Yan Yu, ${ }^{1}$ \\ Rui-Xue Chen, ${ }^{1}$ Ying-Qian Tang, ${ }^{1}$ Ke-Jin Hu, ${ }^{1}$ Cheng-Jing Guan, ${ }^{1}$ Rui Yan ${ }^{1}$
}

To cite: Zeng Y-Q, Qin Z-A, Guo Z-W, et al. Non-linear relationship between basal serum albumin concentration and cardiac arrest in critically ill patients with end-stage renal disease: a crosssectional study. BMJ Open 2022;12:e051721. doi:10.1136/ bmjopen-2021-051721

- Prepublication history for this paper is available online. To view these files, please visit the journal online (http://dx.doi. org/10.1136/bmjopen-2021 051721).

Received 29 March 2021 Accepted 12 January 2022
Check for updates

(c) Author(s) (or their employer(s)) 2022. Re-use permitted under CC BY-NC. No commercial re-use. See rights and permissions. Published by BMJ.

${ }^{1}$ Department of Nephrology, The Affiliated Hospital of Guizhou Medical University, Guiyang, Guizhou, China

${ }^{2}$ Department of Cardiology, The First People's Hospital of Changde City, Changde, China

Correspondence to

Dr Rui Yan; yryr1234@126.com

\section{ABSTRACT}

Objectives The aim of our study was to investigate the association between serum albumin concentration and the risk of cardiac arrest in critically ill patients with end-stage renal disease in the intensive care unit (ICU).

Design This was a secondary analysis.

Setting The Phillip electronic-ICU collaborative database from 2014 to 2015.

Participants This study included 4990 critically ill patients diagnosed with end-stage renal disease.

Primary and secondary outcome measures The exposure of interest was serum albumin concentration. The outcome variable was cardiac arrest.

Results A non-linear relationship was observed between serum albumin concentration and risk of cardiac arrest, with an inflection point of $3.26 \mathrm{~g} / \mathrm{dL}$ after adjusting for potential confounders. The effect sizes and the Cls on the left and right sides of the inflection point were 0.88 (0.65 to 1.19 ) and 0.32 (0.16 to 0.64 ), respectively.

Conclusions Within an albumin range of $3.26-5.6 \mathrm{~g} / \mathrm{dL}$, each $1 \mathrm{~g} / \mathrm{dL}$ increase in serum levels is associated with a $68 \%$ decrease of the risk of cardiac arrest in critically ill patients with end-stage renal disease.

\section{BACKGROUND}

Low serum albumin concentration is a marker of malnutrition and inflammation and has been demonstrated to be a strong predictor of mortality in patients with chronic kidney disease (CKD) and end-stage renal disease (ESRD). A retrospective cohort analysis in 2011 suggested that serum albumin concentration levels were an essential component of a multivariable predictor of mortality in patients with ESRD. ${ }^{1}$ Other studies have found that declining albumin levels in ESRD are associated with higher mortality, whereas increasing levels reduc this risk. ${ }^{2-6}$

Previous studies have shown that among patients with ESRD, cardiovascular disease is a major cause of morbidity and mortality. ${ }^{7}$ Cardiac arrest (CA) is common among these patients and
Strengths and limitations of this study

- This study explores the the non-linear relationship between serum albumin and risk of cardiac arrest.

- This study is a secondary analysis of electronicintensive care unit data, limited by the quality of the database, some variables could not be adjusted.

- The design of this study was cross-sectional study, we cannot infer causal relationship.

- We only studied critically ill patients with end-stage renal disease, therefore, our results cannot be extrapolated to other populations.

carries high morbidity and mortality, ${ }^{89}$ especially in the intensive care unit (ICU). ${ }^{10}$ Although CA is mostly attributed to coronary artery disease in the general population, ESRD-related CA may be mediated by additional mechanism, ${ }^{11} 12$ which have not yet been clearly defined. Thus, primary prevention of CA in the ESRD population is still unattainable.

Previous studies have shown that lower serum albumin levels seem to mediate a higher risk of death, through cardiovascular events, in patients with non-dialysis-dependent CKD and patients with ESRD. ${ }^{13-15}$ Therefore, we aimed to explore the relationship between serum albumin concentration and CA in critically ill patients with ESRD. To this end, we used an electronic ICU (eICU) database to design a cross-sectional study that would address this question and provide pilot data for future or ongoing cohorts studies.

\section{PARTICIPANTS AND METHODS}

Data source

This study used data stored in the Phillip eICU collaborative research database, which is a multicentre ICU database including over 200000 


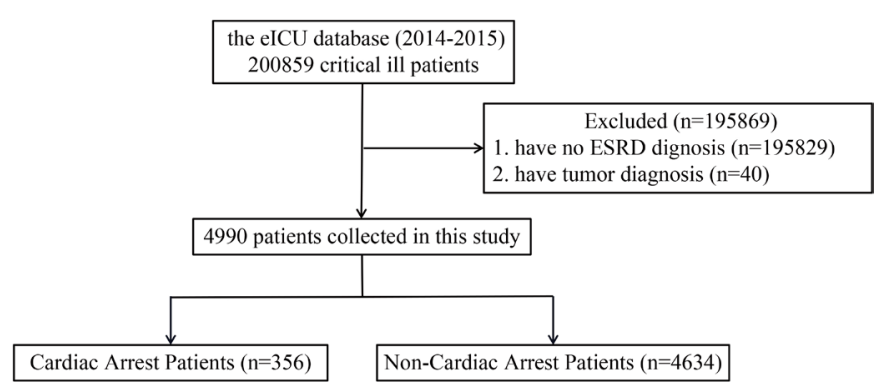

Figure 1 Flow chart of study population. elCU, electronicintensive care unit; ESRD, end-stage renal disease.

admissions between 2014 and 2015. The specific information on the database can be found in the official website (https:/ / eicu-crd.mit.edu/) and previous literature. ${ }^{16}$

\section{Study design}

This is a post hoc analysis of data from critically ill patients with ESRD admitted to the ICUs of 208 hospitals participating in the eICU programme. The study design was a cross-sectional study, and the target independent and outcome variables were serum albumin concentration and CA status. ESRD was defined as a glomerular filtration rate of less than $15 \mathrm{~mL} / \mathrm{min} / 1.73 \mathrm{~m}^{2},{ }^{17}$ and CA was defined as the cessation of cardiac activity associated with unresponsiveness, apnoea and no signs of circulation. ${ }^{18}$

\section{Study population}

All patients in the eICU collabrotive research databases were eligible for inclusion in the present investigation $(\mathrm{n}=200$ 859). Patients diagnosed with ESRD were collected $(n=5030)$. After exclusion of patients who had a diagnosis of malignancy $(n=40)$, a total of 4990 participants were included in data analysis (figure 1).

\section{Variables}

Serum albumin concentration

The serum albumin concentration was the independent variable in this study. We performed the analysis using albumin concentration both as a continuous variable and a categorical variable (tertile).

\section{Cardiac arrest}

CA data were extracted from the eICU diagnosis form. $\mathrm{CA}$ was the outcome variable of this study and was analysed as a binary variable (without $\mathrm{CA}=0$, with $\mathrm{CA}=1$ ).

\section{Covariates}

Covariates included sociodemographic factors (age, sex and race), body mass index (BMI), comorbid conditions (diabetes mellitus (DM), chronic obstructive pulmonary disease (COPD), hypertension and acute respiratory failure (ARF)), other cardiovascular events (acute coronary syndrome (ACS), acute myocardial infarction (AMI), rapid ventricular response (RVR), atrial fibrillation $(\mathrm{AF})$, congestive heart failure (CHF)) and laboratory data (creatinine, haemoglobin, platelet count (PLT), $\mathrm{pH}$, serum calcium and serum potassium). The above covariates were determined to affect $\mathrm{CA}$ based on review of the literature $\mathrm{e}^{1920}$ and clinical experience.

\section{Statistical analysis}

Continuous variables are presented as medians with their IQRs, and categorical variables as total numbers and percentages. Proportions were compared using the $\chi^{2}$, and continuous variables were compared using Wilcoxon rank-sum test. Patients were categorised into two groups according to the outcome variable: the CA group and the non-CA group. Multivariate logistic regression was used to test the association between serum albumin concentration and CA using a series of models. In the first model the covariates was not adjusted, in the second model adjustments were made only for the demographic characteristics, and in the third model all covariates were adjusted, as shown in table 1 . To account for the non-linear relationship between serum albumin concentration and $\mathrm{CA}$, we also used the smooth curve fitting (penalised spline method) to address non-linearity. In addition, two-piecewise function was used to further explain the non-linearity.

All analyses were performed using the statistical software packages R (http://www.R-project.org, The R Foundation) and EmpowerStats (http://www.empowerstats. com, X\&Y Solutions, Boston, Massachusetts, USA). P values less than 0.05 (two sided) were considered statistically significant.

\section{Patient and public involvement}

Patients and the public were not directly involved in the design and conduct of this study.

\section{RESULTS}

A total of 4990 patients were included in this study, with a median age of $63(53,73)$ years, $51.58 \%$ and $29.56 \%$ were Caucasian and African-American, respectively, and $55.31 \%$ were male. The prevalence of CA was $7.13 \%$. All the participants were categorised into two groups according to whether CA occurred, and their demographic and clinical characteristics are detailed in table 1. Compared with the non-CA group, patients in the CA group had higher BMI $(\mathrm{p}=0.022)$ and greater probability of DM ( $p=0.039)$, ARF $(p<0.001)$ and ACS $(p=0.005)$, but a lower probability of COPD $(\mathrm{p}=0.013)$, hypertension $(p<0.001)$ and CHF $(p<0.001)$. Most laboratory data, including creatinine, haemoglobin, albumin and $\mathrm{pH}$, were lower in the CA group. Age, sex, ethnicity, dialysis status, etc showed no differences between the two groups ( $>0.05)$.

Lower serum albumin concentrations were associated with a higher risk of CA (table 2). This association remained statistically significant and was minimally attenuated when adjusted for demographic variables and other covariates. Each $1 \mathrm{~g} / \mathrm{dL}$ increase in serum albumin concentration was associated with a $36 \%$ decrease in CA risk in an unadjusted model (OR (OR): 0.64; $95 \%$ CI 
Table 1 Characteristics of patients in the analysis

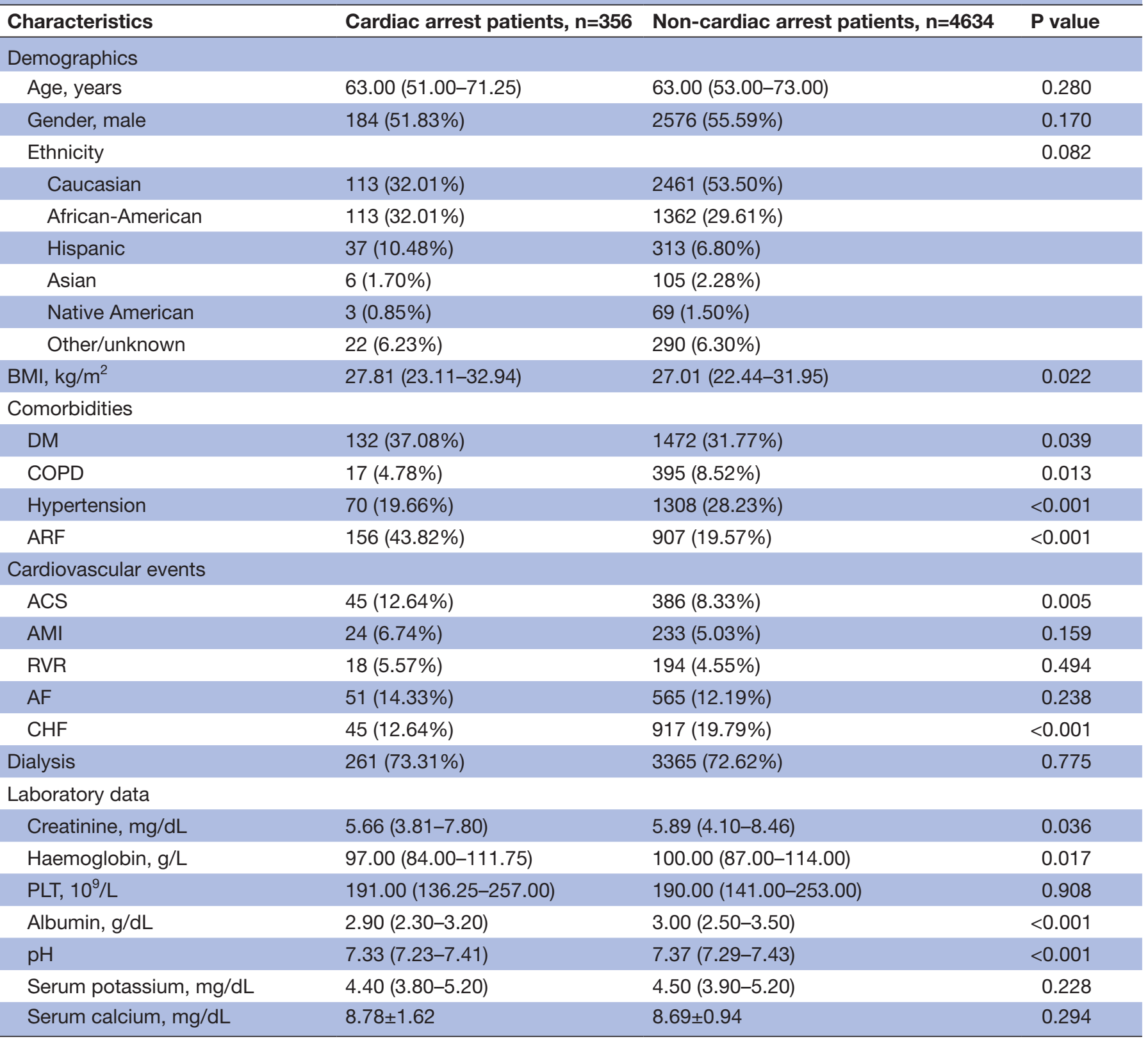

Continuous data presented as median (IQR) and categorical data were reported as $\mathrm{n}(\%)$.

ACS, acute coronary syndrome; AF, atrial fibrillation; AMI, acute myocardial infarction; ARF, acute respiratory failure; BMI, body mass index; CHF, congestive heart failure; COPD, chronic obstructive pulmonary disease; DM, diabetes mellitus; PH, potential of hydrogen; PLT, platelet; RVR, rapid ventricular response.

0.54 to 0.75 ), and a similar OR value was obtained in the fully adjusted model (OR: $0.69 ; 95 \%$ CI 0.55 to 0.86 ). In a sensitivity analysis, we converted serum albumin from a continuous variable to a categorical variable (tertile). In each model, the results were still roughly the same as when albumin was used as a continuous variable (table 2).

Given that serum albumin concentration was a continuous variable, we considered the possibility of a non-linear correlation with CA. Indeed (figure 2), we found that the relationship between serum albumin and risk of CA was non-linear (after adjusting for age, sex, race, BMI, DM, COPD, hypertension, ARF, ACS, AMI, RVR, AF, CHF, creatinine, haemoglobin, PLT, serum albumin, PH and serum calcium, serum potassium). Using a two-piecewise linear regression model, we calculated the inflection point to be $3.26 \mathrm{~g} / \mathrm{dL}$. On the right of the inflection point, the effect size, $95 \%$ CI and $p$ value were $0.32,0.16$ to 0.64 and 0.0013 , respectively. However, no relationship was detected between serum albumin and risk of $\mathrm{CA}$ on the left of the inflection point $(0.88,0.65$ to $1.19,0.4180)$ (table 3$)$.

\section{DISCUSSION}

Numerous studies conducted over the past decades have suggested that cardiovascular events play a key role in 
Table 2 The associations between serum albumin concentrations and cardiac arrest

\begin{tabular}{|c|c|c|c|}
\hline & $\begin{array}{l}\text { Unadjusted } \\
\text { OR (95\% CI) }\end{array}$ & $\begin{array}{l}\text { Model } 1 \\
\text { OR (95\% CI) }\end{array}$ & $\begin{array}{l}\text { Model } 2 \\
\text { OR (95\% CI) }\end{array}$ \\
\hline Albumin & $0.64(0.54 \text { to } 0.75)^{\star \star *}$ & $0.63(0.54 \text { to } 0.74)^{\star \star \star}$ & $0.69(0.55 \text { to } 0.86)^{\star *}$ \\
\hline $\mathrm{T} 1$ & 1.0 & 1.0 & 1.0 \\
\hline $\mathrm{T} 2$ & 0.83 (0.64 to 1.08$)$ & 0.82 (0.63 to 1.06$)$ & 0.82 (0.58 to 1.14$)$ \\
\hline
\end{tabular}

Model 1: model adjusted for age, gender, ethnicity.

Model 2: model further adjusted for BMI, comorbidities including DM, COPD, hypertension and ARF, cardiovascular events including ACS, $\mathrm{AMI}, \mathrm{RVR}, \mathrm{AF}$ and $\mathrm{CHF}$, dialysis, creatinine, haemoglobin, $\mathrm{PLT}$, albumin, $\mathrm{PH}$, serum calcium concentration, serum potassium concentration. ${ }^{*} \mathrm{P}<0.01,{ }^{* *} \mathrm{p}<0.001,{ }^{* * *} \mathrm{p}<0.0001$.

ACS, acute coronary syndrome; AF, atrial fibrillation; AMI, acute myocardial infarction; ARF, acute respiratory failure; BMI, body mass index; $\mathrm{CHF}$, congestive heart failure; COPD, chronic obstructive pulmonary disease; DM, diabetes mellitus; PH, potential of hydrogen; PLT, platelet; RVR, rapid ventricular response.

the mortality of patients with ESRD. ${ }^{721}$ For the critical ill patients with ESRD, CA is a common terminal event. ${ }^{22}$ However, few studies have focused on the factors predisposing this population to CA. Some studies have already shown an association between low serum albumin concentration and higher risk of mortality in patients with ESRD; this association seems to be related to cardiovascular events. ${ }^{13-15}$ Therefore, we used data from 4990 critically ill patients with ESRD to determine if there is a relationship between serum albumin concentration and risk of CA. This cross-sectional study provided several novel results. First, a stable association between higher serum albumin concentration and a decreased risk of CA, after adjustment for potential confounders, was revealed. Second, a non-linear relationship between serum albumin and risk of CA was seen, such as for serum albumin concentration in the range of $3.26-5.6 \mathrm{~g} / \mathrm{dL}$, each $1 \mathrm{~g} / \mathrm{dL}$ increase in

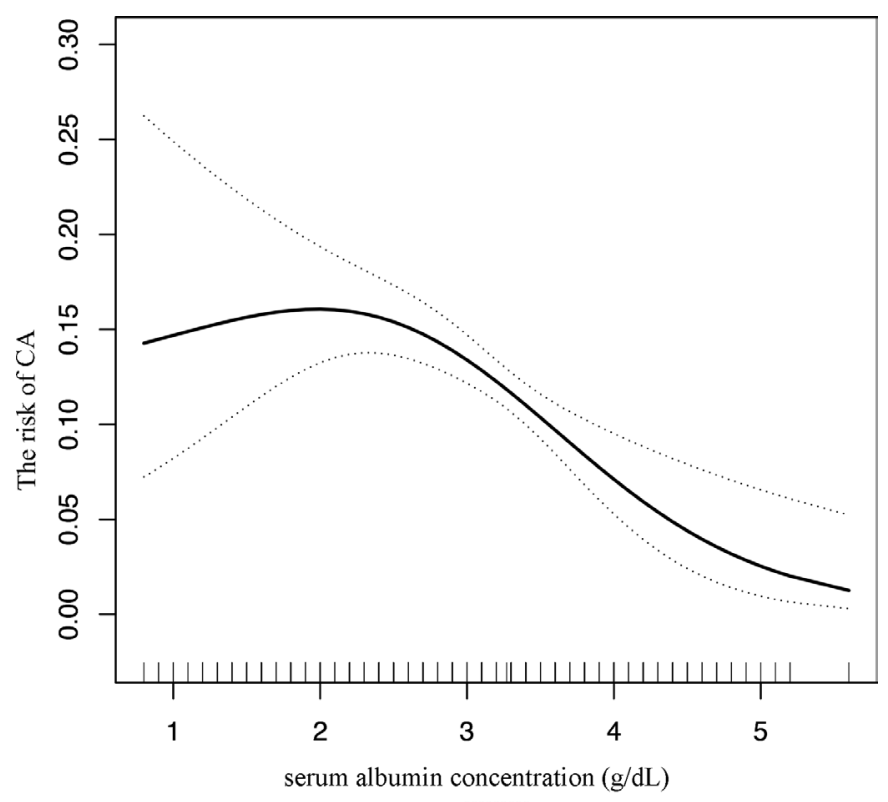

Figure 2 The non-linear relationship between serum albumin concentration and risk of CA. CA, cardiac arrest. serum albumin concentration was associated with a $68 \%$ decrease in CA risk.

Several processes are associated with serum albumin concentration, including the absolute rate of albumin synthesis, the fractional catabolic rate, albumin distribution between the vascular and extravascular compartments, and exogenous loss of albumin. It is well known thay the majority of patients with ESRD have low serum albumin concentration. In our study, up to 2705 patients (54.21\%) had low serum albumin concentrations $(<3.26$ $\mathrm{g} / \mathrm{dL}$ ). There are many reasons for the low serum albumin concentrations in these patients. First, the rate of albumin synthesis is reduced due to the chronic inflammatory state associated with ESRD and malnutrition, often compounded by a commonly prescribed protein-restricted diet. ${ }^{23}$ Second, a large amount of serum albumin is lost in the urine due to the destruction of the nephron. Third, most patients with ESRD require dialysis, which can cause protein loss. ${ }^{24}$ Furthermore, fever, hospital stay, bacteraemia, age, sex and DM are associated with low serum albumin $(<3.8 \mathrm{~g} / \mathrm{dL}) .{ }^{25}$ There are multiple potential mechanisms by which low serum

\begin{tabular}{|c|c|c|c|}
\hline $\begin{array}{l}\text { Inflection point of } \\
\text { serum albumin }\end{array}$ & $\begin{array}{l}\text { Effect } \\
\text { size (OR) }\end{array}$ & $95 \% \mathrm{Cl}$ & $P$ value \\
\hline$<3.26 \mathrm{~g} / \mathrm{dL}$ & 0.88 & (0.65 to 1.19$)$ & 0.4180 \\
\hline$>3.26 \mathrm{~g} / \mathrm{dL}$ & 0.32 & (0.16 to 0.64$)$ & 0.0013 \\
\hline P for loglikely ratio test & 0.013 & & \\
\hline
\end{tabular}

Adjusted: BMI, DM, COPD, hypertension, ARF, ACS, AMI, RVR, AF, CHF, dialysis, creatinine, heamoglobin, PLT, albumin, $\mathrm{PH}$, serum calcium concentration, serum potassium concentration. ACS, acute coronary syndrome; AF, atrial fibrillation; AMI, acute myocardial infarction; ARF, acute respiratory failure; $\mathrm{BMI}$, body mass index; CHF, congestive heart failure; COPD, chronic obstructive pulmonary disease; DM, diabetes mellitus; $\mathrm{PH}$, potential of hydrogen; PLT, platelet; RVR, rapid ventricular response. 
albumin concentration may result in adverse clinical outcomes. As a major source of sulfhydryl groups, serum albumin binds some toxic lipid moieties and contributes, to some extent, to the removal of uraemic toxins. Meanwhile, serum albumin has the anticoagulant and antithrombotic effects, which may be due to the binding of nitric oxide (NO) free radicals. ${ }^{26}$ Furthermore, studies have suggested that albumin may act as a reservoir for NO. ${ }^{27}$ Therefore, low serum albumin concentration may reduce NO-induced vasodilatation, thereby increasing cardiovascular mortality in patients with ESRD. However, additional studies are required to understand the biological mechanisms linking low serum albumin concentration with the risk of CA.

Although we have discovered a relationship between low serum albumin and the risk of CA, we should realise that there are still many challenges. First, it is still not clear whether the correction of serum albumin concentrations improves outcomes. There is no clinical evidence that interventions targeting an increase of serum albumin above a pre-specified threshold can lead to better clinical outcomes in the ESRD population. Second, it is possible that the interventions to increase serum albumin concentrations may be associated with adverse patient outcomes. ${ }^{28}$ Additionally, in patients with ESRD, serum albumin concentrations may reflect a complex interplay between variables. Therefore, further clinical studies are needed to explore the effective method of albumin supplementation and evaluate its effectiveness in improving patient outcomes. Notwithstanding these caveats, our study provides evidence that serum albumin concentration may be a useful clinical tool for clinicians in risk-stratifying patients for the occurrence of CA.

The strengths of this study are obvious. First, this is the first study to analyse the relationship between serum albumin concentration and the risk of CA in critically ill patients with ESRD with a large sample size. Second, The results were robust when we determined the effect of serum albumin concentration analysed both as a continuous and categorical variable. Third, this study provided a novel perspective that low serum albumin concentration is associated with a common terminal event-CA in the ICU, which may be the underlying mechanism leading to poor prognosis of patients in patients with ESRD in the ICU. There are some limitations to our study. First, this study only adjusted for measured confounders. It is, therefore, possible that the association between serum albumin concentration and CA could be affected by unmeasured confounders. Second, given this study focuses on the relationship between albumin and CA, other possible factors that may be related to CA such as different comorbidities need to be further discussed in the future.

\section{CONCLUSION}

Previous studies have shown that serum albumin concentration is associated with mortality of patients with ESRD, which seems to be related to cardiovascular events. Our study demonstrated the presence of a definite relationship between low serum albumin concentration and risk of CA in an ESRD population very prone to cardiovascular morbidity and mortality. Given that serum albumin concentration levels can be modified in this population, further studies are urgently needed to determine whether such modification is worthwhile undertaking.

Acknowledgements The authors would like to thank all the participants in the study.

Contributors Z-AQ completed the web-based training courses and the Protecting Human Research Participants examination (№. 36208651) and obtained permission to extract data from the elCU collaborative research database. Y-QZ contributed to conception and design of the study and analysed and interpreted data. Z-WG, BL, $\mathrm{H}-\mathrm{YY}, \mathrm{R}-\mathrm{XC}, \mathrm{Y}-\mathrm{QT}, \mathrm{K}-\mathrm{JH}$ and C-JG reviewed the data. Y-QZ and RY contributed to writing and revising the manuscript. $\mathrm{Y}-\mathrm{QZ}$ is responsible for the overall content as the guarantor. All authors reviewed the manuscript and approved the final version for publication.

Funding This work was supported by the National Natural Science Foundation of China (81960140) and the Guizhou Provincial Natural Science Foundation (ZK(2021)379).

\section{Competing interests None declared.}

Patient and public involvement Patients and/or the public were not involved in the design, or conduct, or reporting, or dissemination plans of this research.

Patient consent for publication Not applicable.

Ethics approval The use of this database was approved by the institutional review board of Massachusetts Institute of Technology (Cambridge, MA, USA). After completing the web-based training courses and the Protecting Human Research Participants examination (№. 36208651), we obtained permission to extract data from the eICU collaborative research database.

Provenance and peer review Not commissioned; externally peer reviewed.

Data availability statement Data are available in a public, open access repository. All data relevant to the study are stored in the Phillip elCU collaborative research database, and can be got in the official website (https://eicu-crd.mit.edu/) after completing the web-based training courses and examination.

Open access This is an open access article distributed in accordance with the Creative Commons Attribution Non Commercial (CC BY-NC 4.0) license, which permits others to distribute, remix, adapt, build upon this work non-commercially, and license their derivative works on different terms, provided the original work is properly cited, appropriate credit is given, any changes made indicated, and the use is non-commercial. See: http://creativecommons.org/licenses/by-nc/4.0/.

ORCID iD

Yong-Qin Zeng http://orcid.org/0000-0003-1400-3635

\section{REFERENCES}

1 Wagner M, Ansell D, Kent DM, et al. Predicting mortality in incident dialysis patients: an analysis of the United Kingdom renal registry. Am J Kidney Dis 2011;57:894-902.

2 Diaz-Buxo JA, Lowrie EG, Lew NL, et al. Associates of mortality among peritoneal dialysis patients with special reference to peritoneal transport rates and solute clearance. Am J Kidney Dis 1999;33:523-34.

3 Kalantar-Zadeh K, Kilpatrick RD, Kuwae N, et al. Revisiting mortality predictability of serum albumin in the dialysis population: time dependency, longitudinal changes and population-attributable fraction. Nephrol Dial Transplant 2005;20:1880-8.

4 Pifer TB, McCullough KP, Port FK, et al. Mortality risk in hemodialysis patients and changes in nutritional indicators: DOPPS. Kidney Int 2002;62:2238-45.

5 Mehrotra R, Duong U, Jiwakanon S, et al. Serum albumin as a predictor of mortality in peritoneal dialysis: comparisons with hemodialysis. Am J Kidney Dis 2011;58:418-28.

6 Singh T, Astor BC, Waheed S. End-Stage renal disease patients with low serum albumin: is peritoneal dialysis an option? Perit Dial Int 2019;39:562-7. 
7 Sud M, Tangri N, Pintilie M, et al. Risk of end-stage renal disease and death after cardiovascular events in chronic kidney disease. Circulation 2014;130:458-65.

8 Alqahtani F, Almustafa A, Shah K, et al. Sudden cardiac arrest in endstage renal disease patients on dialysis: a nationwide study. Pacing Clin Electrophysiol 2018;41:1467-75.

9 Surana SP, Pun PH, Keithi-Reddy SR, et al. Sudden cardiac arrest in ESRD patients. Clin Nephrol 2014;81:121-31.

10 Moskowitz A, Berg KM, Cocchi MN, et al. Cardiac arrest in the intensive care unit: an assessment of preventability. Resuscitation 2019;145:15-20.

11 Chan KE, Newton-Cheh C, Gusella JF, et al. Heritability of risk for sudden cardiac arrest in ESRD. J Am Soc Nephrol 2015;26:2815-20.

12 Herzog CA, Mangrum JM, Passman R. Sudden cardiac death and dialysis patients. Semin Dial 2008;21:300-7.

13 Muntner P, He J, Astor BC, et al. Traditional and nontraditional risk factors predict coronary heart disease in chronic kidney disease: results from the atherosclerosis risk in communities study. J Am Soc Nephrol 2005;16:529-38.

14 Weiner DE, Tighiouart $\mathrm{H}$, Elsayed EF, et al. The relationship between nontraditional risk factors and outcomes in individuals with stage 3 to 4 CKD. Am J Kidney Dis 2008;51:212-23.

15 Molnar MZ, Kovesdy CP, Bunnapradist S, et al. Associations of pretransplant serum albumin with post-transplant outcomes in kidney transplant recipients. Am J Transplant 2011;11:1006-15.

16 Pollard TJ, Johnson AEW, Raffa JD, et al. The elCU Collaborative research database, a freely available multi-center database for critical care research. Sci Data 2018;5:180178.

17 Levey AS, Coresh J, Balk E, et al. National Kidney Foundation practice guidelines for chronic kidney disease: evaluation, classification, and stratification. Ann Intern Med 2003;139:137-47.
18 Buxton AE, Calkins H, Callans DJ. ACC/ AHA/HRS 2006 key data elements and definitions for electrophysiological studies and procedures: a report of the American College of Cardiology/ American Heart Association Task Force on Clinical Data Standards (ACC/AHA/HRS Writing Committee to Develop Data Standards on Electrophysiology.

19 Ohlsson MA, Kennedy LMA, Juhlin T, et al. Midlife risk factor exposure and incidence of cardiac arrest depending on cardiac or non-cardiac origin. Int J Cardiol 2017;240:398-402.

20 Ryden A, Engdahl J, Claesson A, et al. Is atrial fibrillation a risk factor for in-hospital cardiac arrest?: a Swedish retrospective cohort study. BMJ Open 2018;8:e022092.

21 Di Lullo L, House A, Gorini A, et al. Chronic kidney disease and cardiovascular complications. Heart Fail Rev 2015;20:259-72.

22 Salenger PV. Sudden cardiac death in end-stage renal disease. Cardiol Clin 2019;37:319-26.

23 Fouque D, Guebre-Egziabher F. Do low-protein diets work in chronic kidney disease patients? Semin Nephrol 2009;29:30-8.

24 Kalantar-Zadeh K, Ficociello LH, Bazzanella J, et al. Slipping through the pores: hypoalbuminemia and albumin loss during hemodialysis. Int J Nephrol Renovasc Dis 2021;14:11-21.

25 Sridhar NR, Josyula S. Hypoalbuminemia in hemodialyzed end stage renal disease patients: risk factors and relationships--a 2 year single center study. BMC Nephrol 2013;14:242.

26 Paar M, Rossmann C, Nusshold C, et al. Anticoagulant action of low, physiologic, and high albumin levels in whole blood. PLoS One 2017;12:e0182997

27 Minamiyama Y, Takemura S, Inoue M. Albumin is an important vascular tonus regulator as a reservoir of nitric oxide. Biochem Biophys Res Commun 1996;225:112-5

28 Conner BJ. Treating hypoalbuminemia. Vet Clin North Am Small Anim Pract 2017;47:451-9. 